\title{
Mechanisms of Tumor-Associated Edema: A Review
}

\author{
Rolando F. Del Maestro, Joseph F. Megyesi and Catherine L. Farrell
}

\begin{abstract}
An understanding of the mechanisms responsible for tumor-associated edema involves the elucidation of the role played by a number of intra-related processes. These include (i) the permeability of new tumor microvessels that are associated with tumor angiogenesis; (ii) alterations in microvascular permeability due to factors secreted by tumor cells; (iii) immunological mechanisms and (iv) increased microvessel permeability associated with inflammation. The rationale for a role for inflammatory processes in tumor-associated edema has been outlined and the role of non-steroidal anti-inflammatory drugs in modulating experimental and human tumor-associated edema has been explored.
\end{abstract}

RÉSUMÉ: Revue des mécanismes de l'oedème associé aux tumeurs La compréhension des mécanismes responsables de l'oedème associé à des tumeurs implique l'élucidation du rôle de certains processus inter-reliés. Ce sont (I) la perméabilité des nouveaux microvaisseaux de la tumeur qui sont associés à l'angiogénèse tumorale; (II) les altérations de la perméabilité microvasculaire due à des facteurs sécrétés par les cellules tumorales; (III) des mécanismes immunologiques et (IV) une perméabilité accrue des microvaisseaux associée à l'inflammation. Nous justifions le rôle de processus inflammatoires dans l'oedème associé aux tumeurs et nous explorons le rôle des anti-inflammatoires nonstéroïdiens dans la modulation de l'oedème associé aux tumeurs, dans le contexte expérimental et humain.

Can. J. Neurol.Sci. 1990; 17: 177-183

The growth of human intracerebral tumors is associated with the development of tumor-associated edema which is responsible for significant patient morbidity and mortality. The control of tumor-associated edema is an important component of patient management.

The understanding of the mechanisms responsible for cerebral edema associated with tumor growth involves the elucidation of the contribution of a number of inter-relating processes (Figure 1). Conceptually, four dynamic processes may be considered: 1) the permeability of new microvessels associated with tumor angiogenesis; 2) increased microvascular permeability due to factors secreted by tumor cells; 3 ) immunological mechanisms and 4) increased microvascular permeability associated with the inflammatory process which may depend on both the presence and growth of the tumor.

In this communication, an attempt will be made to evaluate the role of each of these suggested mechanisms in the murine C6 spheroid implantation model 1,2 and human cerebral tumors with an emphasis on the possible role of inflammatory processes and the influence of non-steroidal anti-inflammatory drugs (NSAID's).

\section{Definitions}

Cerebral edema may be defined as an increase in brain volume due to elevated water and sodium content. Tumor-associated edema may be considered to be a specific situation in which there is an increase in water content of brain tissue which results from the presence and/or growth of a cerebral tumor. The term, peritumoral edema, is frequently used ${ }^{3}$ however, alterations in water content may be found large distances from the tumor and may also involve the corpus callosum and the contralateral hemisphere (Figure 2). It would appear that the term "tumorassociated edema" may more accurately reflect the pathophysiological events occurring during tumor growth which result in alterations in cerebral water content.

Tumor-associated edema is usually visualized on a contrast enhanced computerized tomography scan as an area of hypodensity surrounding the region of tumor enhancement (Figure 2) or as a region of increased $T_{1}$ or $T_{2}$ signal surrounding the gadolinium enhanced area on a magnetic resonance image. In metastatic and extra-axial tumors, the localization and quantitation of tumor-associated edema is usually possible using these imaging techniques. However, in infiltrating malignant cerebral tumors

From the Brain Research Laboratories, Experimental Research Unit, Department of Clinical Neurological Sciences, University of Western Ontario, London

Reprint requests to: Dr. R. F. Del Maestro, Brain Research Laboratories, Victoria Hospital, 375 South Street, London, Ontario, Canada N6A 4G5 


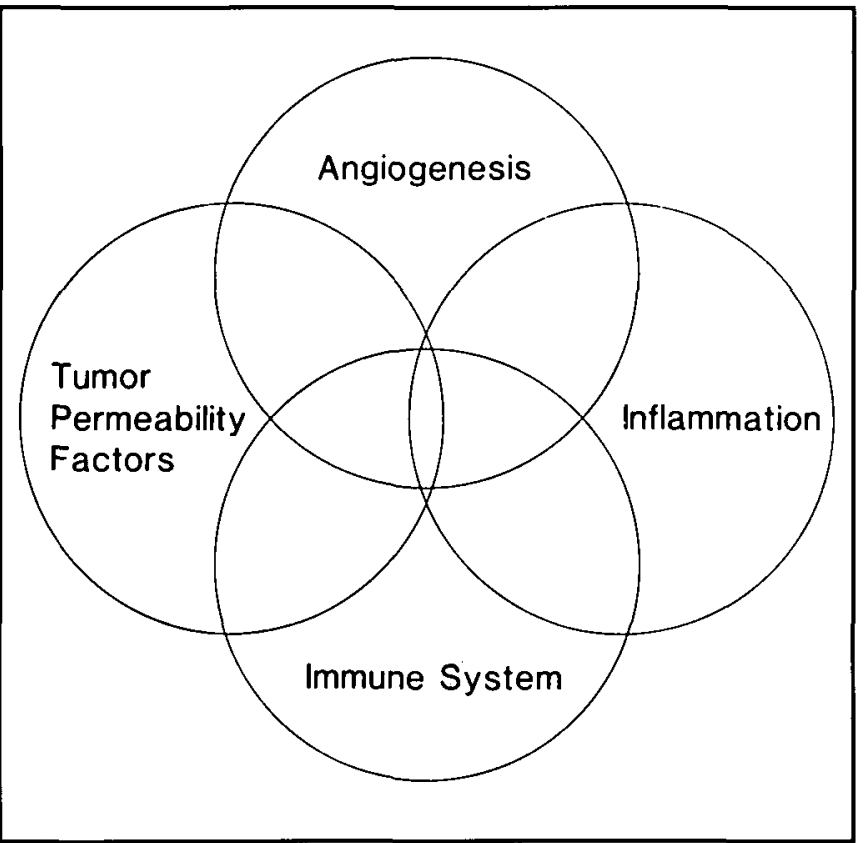

Figure I-Conceptual model for the inter-relationship of four factors which may be responsible for tumor-associated edema.

and in low grade tumors with no enhancement, the differentiation of tumor infiltrated cerebral tissue from tumor-associated edema cannot be accurately carried out.2,4 Tumor cells are found large distances from the major tumor mass in many malignant glial tumors. ${ }^{5}$ It may be reasonable to describe the computerized tomogram in these situations as having tumor-associated hypodensity which outlines what is seen but does not identify the pathophysiology of the process.

\section{Mechanisms of Tumor-Associated Edema \\ Tumor Angiogenesis}

The progressive growth of solid tumors and their metastases depends on the induction of new microvessels from the host tissue called angiogenesis. 6 This may be considered a multi-stage cascade of events involving morphological and biochemical alterations in a variety of microvessels co-ordinated by a number of interacting growth factors. It is not unique to tumors occurring in such processes as chronic inflammation, wound repair and embryogenesis. ${ }^{6}$ Hardman ${ }^{7}$ carried out the first comprehensive studies on angiogenesis in malignant human glial tumors and outlined a number of key points of cerebral tumor angiogenesis: 1) that new tumor vessels develop from previously existing vessels; 2) that endothelial proliferation is common in malignant glial tumors; 3 ) that central necrosis is common which he suggested was secondary to vessel obstruction. Glioblastoma multiforme has been found to be the most vascular of a group of tumors assessed by Brem. ${ }^{8}$

Figure 3 outlines one concept of the "angiogenic cascade". Initiation events are those changes in specific endothelial cells and their microenvironments which begin the process of angiogenesis before endothelial cell proliferation occurs. Initially basement membrane and vessel wall component degradation occurs which is felt to represent local proteolysis by endothelial cells in response to biochemical and/or biophysical stimuli associated with the continued growth of the tumor. ${ }^{6}$ These alter-

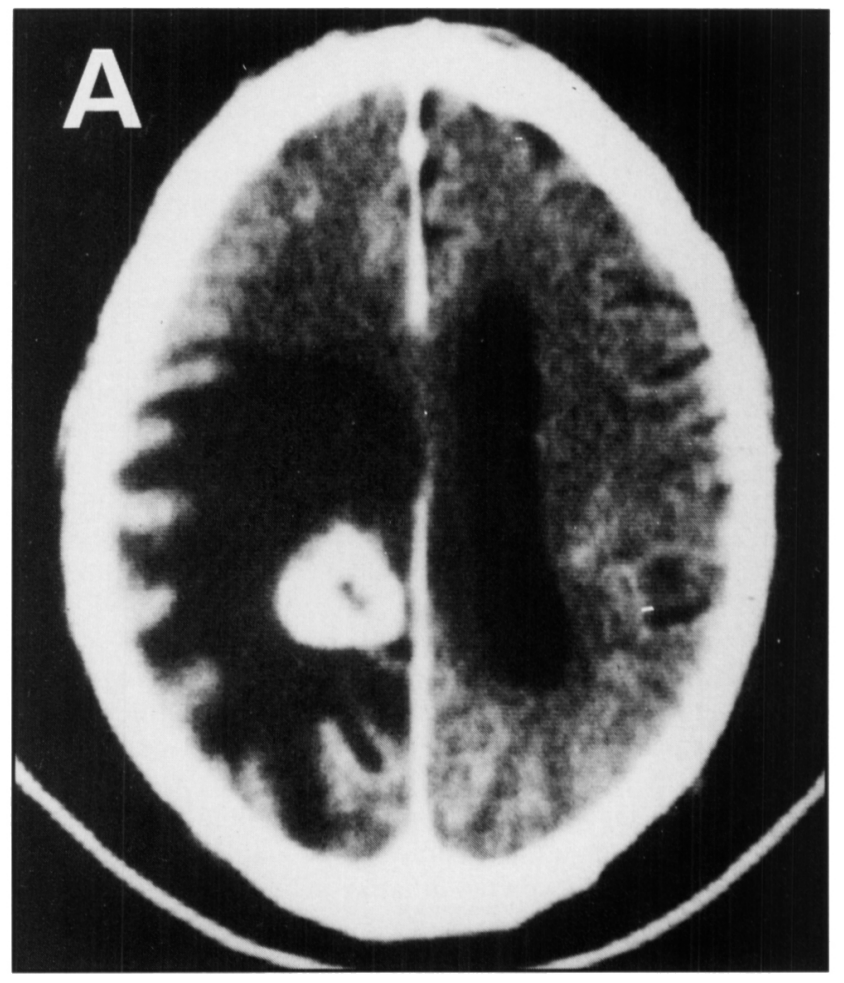

Figure $2 A$. Enhanced CT scan of a single metastatic lesion in the left parietal lobe and the region of surrounding hypodensity; tumorassociated edema.

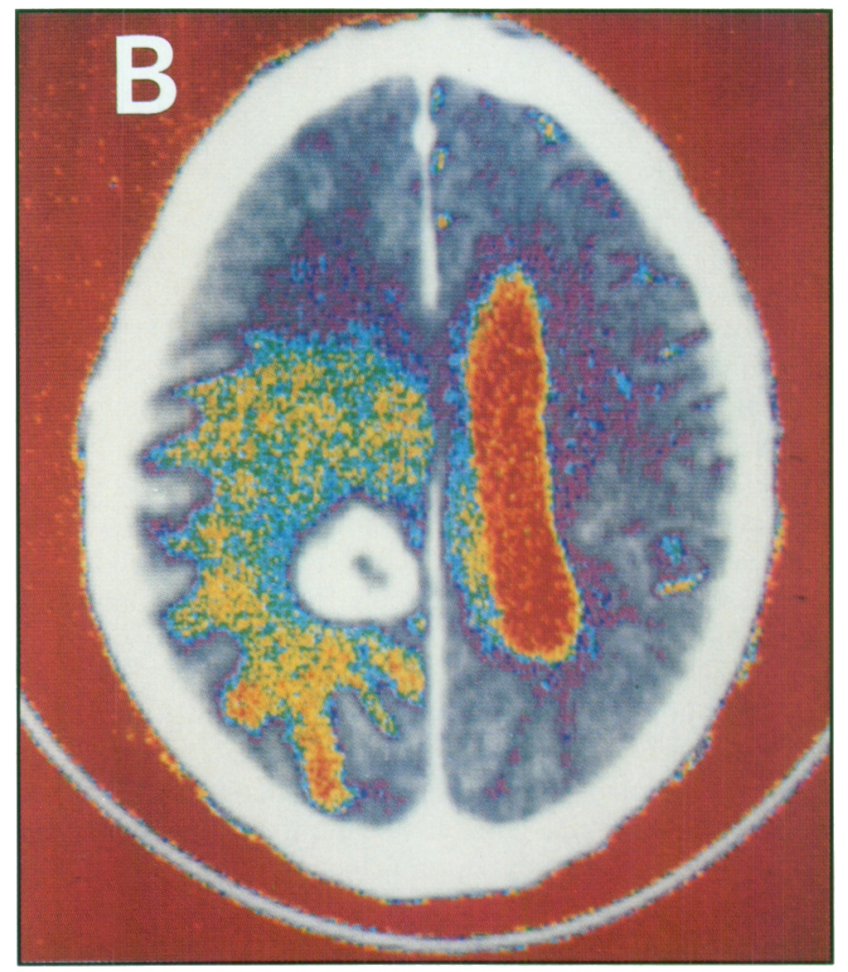

Figure 2B. Colour enhancement of the same CT scan showing the extent of the tumor-associated edema in the corpus callosum and in the white matter of the contralateral hemisphere. 
ations in the vessel wall allow endothelial cell elongation and migration. Endothelial cell proliferation occurs which lengthens the new microvessel loop and directional influences are exerted which result in closed loops flowing with blood elements. Termination events also occur in some specific normal situations such as wound healing and embryogenesis. The role played by termination events in the necrosis seen in cerebral tumors is not known.

At the blood brain interface, a dynamic interactive system called the blood brain barrier modulates the flux of a wide variety of molecules into brain. The anatomical site of the blood brain barrier is the cerebral endothelium. Blood-borne molecules cross the vessel wall via three routes: (a) a paracellular route through spaces in the junctional regions; (b) through fenestrae and/or (c) across the cytoplasm via so called vesicular transport. Cerebral vessels possessing a blood brain barrier appear to restrict the passage of macromolecules by all three of these routes.

The implantation of $\mathrm{C} 6$ spheroids into murine brain or muscle, clearly very different vascular beds, induced microvessels with endothelial cell morphological features which were not quantitatively distinguishable. 12 These results suggest that irrespective of the host tissue microvessels in which they are grown, C6 astrocytoma tumor cells organize the development and the final morphological features of the microvessels which vascularize them. Specific endothelial cell morphological changes are seen in tumor vessel profiles from the C6 astrocytoma spheroid implantation model. ${ }^{9}$ Sixty percent of tumor vessel profiles had junctional abnormalities and occasional fenestrae were seen. Vesicle density profiles were not significantly different from that found in normal rat brain microvessels. Quantitative studies of microvessel endothelium in glioblastoma multiforme have also been carried out and demonstrate large endothelial gaps in a small percentage of vessels and interendothelial junctions with enlarged distentions. ${ }^{10}$ No significant alterations in pinocytotic vesicle numbers or arrangements was seen and fenestrae were not encountered. These results demonstrate that distinct quantitative morphological differences are found differentiating normal rat $^{9}$ or human cerebral endothelium 11 from endothelium of experimental and human malignant glial tumors. Endothelial paracellular routes through spaces in the endothelial junctional region may represent the morphological equivalent of the large pore allowing increased fluid and macromolecular flux through tumor microvessel endothelium.

The leakage of albumin-bound Evans Blue (EB) into growing C6 astrocytoma tumors parallels the development of the tumor vasculature. ${ }^{1}$ There is no detectable leakage prior to vessel ingrowth, increasing leakage with increasing size of vascularized tumors and significant variability of leakage in large necrotic tumors. The increased permeability seen during the early stages of $\mathrm{C} 6$ astrocytoma growth may be predominantly due to protein and fluid flux from new, highly permeable microvessels induced by an activated angiogenic process and/or from previously normal cerebral capillaries and post-capillary venules involved in the initiation events of the angiogenic cascade. These mechanisms may also play a prominent role in edema associated with the fast growing edge of larger tumors and be responsible for the ring enhancement seen in some human tumors on computerized tomography scans.

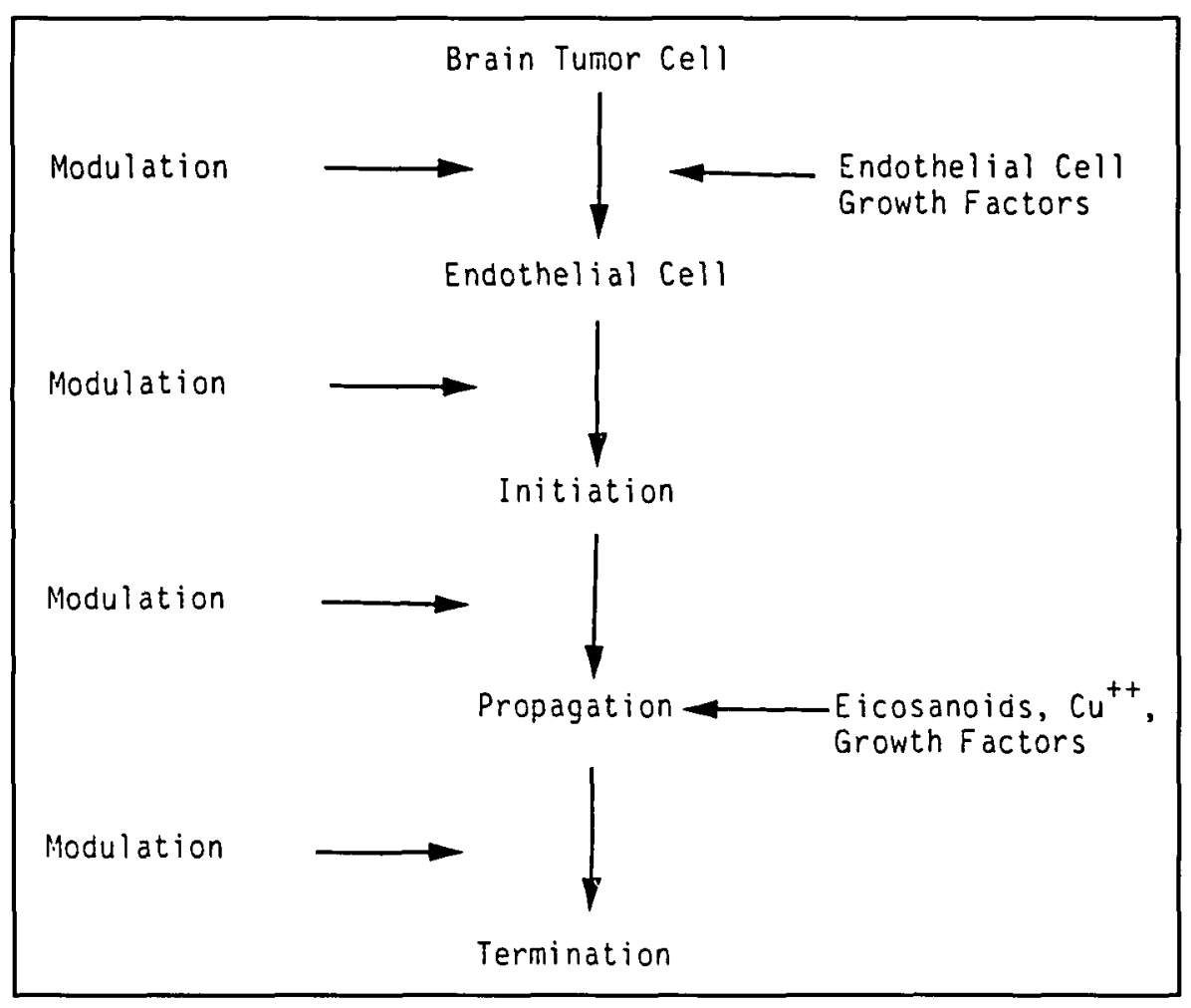

Figure 3 - The angiogenic cascade showing sites for possible therapeutic modulation. 


\section{Tumor Permeability Factors}

Two distinct vascular events appear to occur with continued C6 astrocytoma growth: 1) the proliferation of new blood vessels, "angiogenesis" and 2) the infiltration of tumor cells directly along and/or in the vicinity of established blood vessels in peritumoral brain, altering their morphological and functional characteristics, "tumor induced vascular modification".' The majority of microvessels are structurally normal in C6 astrocytoma peritumoral tissue. However, a small percentage of vessels associated with tumor cells had endothelial abnormalities. ${ }^{9}$ In glioblastoma multiforme, peritumoral vessels enveloped by a layer of tumor cells were abnormal. ${ }^{13}$ The presence of endothelial alterations in human peritumoral vessels not in direct contact with tumor cells suggested the action of one or more diffusible factors which act at a distance from the major tumor mass. ${ }^{13}$ It has been suggested that the edema associated with meningiomas may be related to mediators secreted by meningioma cells which increase microvessel permeability. ${ }^{14} \mathrm{~A}$ number of tumor cell lines including $\mathrm{C} 6$ astrocytoma ${ }^{15}$ and meningiomas secrete prostaglandin $\mathrm{E}_{2}\left(\mathrm{PGE}_{2}\right)$ and thromboxane $\mathrm{B}_{2} \cdot{ }^{16}$ At least two different diffusible factors capable of increasing microvascular permeability have been identified in the supernatant of cultured $\mathrm{C} 6$ glioma cells ${ }^{17}$ and a vascular permeability factor, which does not appear to be an eicosanoid, has been partially characterized from cultured human brain tumor explants. ${ }^{18.19}$ The action of this human vascular permeability factor appears to be inhibited by dexamethasone, but not by indomethacin and this mechanism may be one reason for the effectiveness of corticosteroids in the management of cerebral edema, but not other forms of edema. ${ }^{18,19}$ The permeability increase seen in previously normal peritumor microvessels may be dependent on the types and concentrations of a number of different diffusible factors. These diffusible factors may be responsible for the induction of the distinct endothelial cell morphological changes seen in peritumoral tissue.9,13 The role played by these permeability increasing factors in altering the permeability of the new microvessels associated with angiogenesis is unknown. The inter-relationship, if any, between these permeability factors and those factors responsible for the induction of angiogenesis has not been defined.

\section{Immunological Mechanisms}

Chiu et al.20 found that $\mathrm{C} 6$ astrocytoma cells injected intracranially into Wistar rats evoked a weakly positive skin test reaction to the tumor cells, but did not stimulate cell mediated cytotoxicity. No impairment of peripheral blood T-cell numbers, responsiveness or subsets were found when a variety of glioma patients were compared to controls. ${ }^{21}$ However, the production by glioma cells of immunomodulators such as $\mathrm{PGE}_{2}$ and an interleukin-1-like factor, 22,23 along with a suppressor factor which inhibits interleukin-2 mediated T-cell activation has been reported. ${ }^{24}$ Lymphokine activated killer cells mediate the killing of human glioma cells in vitro 25 and this modality is being explored as a treatment for malignant glioma; however, significant cerebral edema has been seen as a complication of therapy. ${ }^{26}$ The intravenous administration of interleukin- 2 to patients with malignant gliomas and to patients with no known cerebral disease results in increased tumor-associated edema and brain water content, respectively. 27 These results suggest that at a tissue level the growth of intracerebral tumors may be associated with alterations in local immunological mechanisms, some of which may induce cellular injury and alter microvascular permeability. The role played by the immune system in inducing permeability alterations is unclear, but it appears to warrant further investigation.

\section{Inflammatory Process}

The surgical manipulation necessary for the cerebral implantation of a C6 astrocytoma spheroid or cell suspensions is associated with an inflammatory response. The growth of C6 astrocytoma spheroids intracerebrally recruits increasing numbers of inflammatory cells into the tumor as measured by a specific myeloperoxidase assay (Lordo and Del Maestro, unpublished results). Immunohistological studies have demonstrated macrophage accumulation in and around human tumors associated with edema. ${ }^{28}$ Inflammatory cells such as polymorphonuclear leukocytes and macrophages possess impressive arsenals consisting of at least four major components. ${ }^{29,30}$ These are the release of specific enzymes and other reactive components from specialized granules; the release of platelet activating factor (PAF); ${ }^{31}$ the formation of specific arachidonic acid products, the eicosanoids, and the generation of superoxide anion radical and the resultant family of reactive products. $29,30,32$

\section{Enzymes}

Polymorphonuclear leukocytes contain granules of two distinct types: primary granules containing myeloperoxidase, acid hydrolases, glycosidases and cationic proteins and specific granules containing alkaline phosphase, lactoferrin and lysozyme. Cellular injury leading to permeability increase may be associated with the release of molecular species localized in granules from inflammatory cells.

\section{Platelet Activating Factor}

Platelet activating factor can be released by leukocytes or it may already be present in endothelial cells. ${ }^{31}$ It stimulates the aggregation of platelets which in turn release vasoactive substances. In addition, it may trigger neutrophil aggregation, degranulation and chemotaxis. In response to some stimuli, it may augment the generation of oxygen radicals.

\section{Eicosanoids}

A number of eicosanoids such as $\mathrm{PGE}_{1}, \mathrm{PGE}_{2}$ and $\mathrm{PGF}_{2}$ are known to increase microvascular permeability in non-neural tissues. ${ }^{33}$ Indomethacin reduces both eicosanoid synthesis and microvascular leakage in the hamster cheek pouch model. ${ }^{33} \mathrm{~A}$ correlation has been observed between increased tissue leukotriene $\mathrm{C}_{4}$ and human tumor associated edema. ${ }^{34}$ Leukotriene $C_{4}$ and $D_{4}$ are known to increase microvascular permeability. ${ }^{35}$ Indomethacin is known to decrease eicosanoid synthesis in rat brain 36 and has been shown to significantly decrease the extravasation of EB in the C6 astrocytoma spheroid implantation model. ${ }^{37}$ Eicosanoids may also play a role in the angiogenic cascade and their inhibition by ibuprofen may result in decreased tumor growth in the $\mathrm{C} 6$ astrocytoma spheroid implantation model. ${ }^{38}$

\section{Oxygen Derived Free Radicals}

Free radicals are important mediators of tissue injury. ${ }^{29,30} \mathrm{~A}$ variety of macromolecules which constitute the extracellular space, cell membranes and constituent proteins are susceptible 
to free radical-induced injury. In model systems, the extracellular generation of free radicals results in increased microvascular permeability39,40,4I and the intravascular generation of free radical species results in similar permeability changes. ${ }^{42}$ The sources of free radicals in inflammation are inflammatory cells such as polymorphonuclear leukocytes, macrophages and lymphocytes, ${ }^{43}$ eicosanoid metabolism ${ }^{29}$ and lipid peroxidation reactions. ${ }^{22} \mathrm{~A}$ potent inhibitor of free radical induced lipid peroxidation (U74006F) ${ }^{45}$ modulates both ischemic ${ }^{46,47}$ and traumatic injury 48 in animal models of central nervous system disease. This compound prevented blood brain barrier injury after experimental subarachnoid hemorrhage in rats. ${ }^{49}$ The role played by lipid peroxidation in tumor-associated edema is unknown; however, the ineffectiveness of U74006F in modulating the permeability increase seen in the $\mathrm{C} 6$ astrocytoma model, suggests that lipid peroxidation may not play a prominent role in this process. 50

\section{Influence of NSAIDs}

The exact mechanisms by which steroid therapy modulates tumor-associated edema is unclear and a number of mechanisms have been proposed which may contribute to tumor-associated edema ${ }^{18,19,37,51}$ acting on one or more processes just described. There is no question, however, that steroids are efficacious in reducing tumor-associated edema both experimentally and clinically. 52 Unfortunately, steroids have not been shown to be effective in human cerebral trauma, ${ }^{53}$ human cerebral infarction ${ }^{54}$ or human cerebral hemorrhage. ${ }^{55}$ This information would suggest that steroids are not effective in all conditions in which an alteration in blood brain barrier permeability is seen. Indeed steroids appear to be useful in two specific situations: tumorassociated edema and cerebral edema associated with infection and inflammation (cerebral abscess and bacterial meningitis); so called granulocytic brain edema. $56,57,58$ The effectiveness of steroids in these two types of cerebral edema would suggest the possibility of some common mechanism(s) operational in both. The influence of steroids on inflammatory and/or immune processes present in infection and during tumor growth may be one common thread.

The prolonged use of high dose, long term steroid therapy is associated with profound complications ${ }^{59}$ and the development of alternate methods to modulate tumor-associated edema appear warranted. Ibuprofen and indomethacin had been shown to be effective in reducing edema associated with intrahepatic carcinosarcomas in rats. ${ }^{60}$ The $\mathrm{C} 6$ spheroid implantation model has been used to assess the influence of the corticosteroids, dexamethasone and methylprednisolone, compared to the NSAIDs, indomethacin and ibuprofen (cyclo-oxygenase inhibitors) on the extravasation of EB into tumor and peritumoral regions. The results using 48-hour treatment suggested that the NSAIDs tested in the concentrations used decreased EB extravasation into both tumor and peritumoral tissue. ${ }^{37}$ Other investigators using a similar protocol have found clinical improvement and decreased water content in the spinal cords of animals with extradural tumors which were pretreated with indomethacin. ${ }^{61,62}$ Long term high dose therapy with ibuprofen in the C6 spheroid implantation model resulted in a statistically significant decrease in intracranial tumor growth. ${ }^{38}$ Weissman and Stewart ${ }^{63}$ using a VX2 rabbit brain tumor model have failed to find any influence of indomethacin or meclofenamate on tumor- associated edema. It would therefore appear that cerebral tumor models may respond in a differential manner to NSAIDs possibly related to the role that inflammatory and/or immune processes may be playing at the particular stage of tumor growth when treatment occurs. Length of treatment and dose may also play a role. In a small clinical trial, ibuprofen improved the Karnofsky rating of about $40 \%$ of the patients with cerebral tumors and tumor-associated edema. ${ }^{64}$ Patients intolerant of steroids or steroid dependent may be subgroups that could benefit from being placed on NSAIDs. Further studies are warranted before suggesting a role for NSAIDs in the treatment of patients with symptomatic tumor-associated edema.

The mechanism(s) by which ibuprofen may decrease EB extravasation in experimental models or improve brain tumor patient symptoms are unknown. A number of mechanisms could be suggested including (a) modulation of endothelial permeability of tumor microvessels; (b) modulation of endothelial permeability in peritumoral tissue; (c) an influence on inflammatory cell mediated permeability or tissue injury; (d) a direct influence of eicosanoid inhibition on cell function and (e) alterations in flow in tumor or peritumoral tissue secondary to prostaglandin inhibition.

The etiology of tumor-associated edema may be multifactorial. During the growth of a specific cerebral tumor, a number of different mechanisms may be functional which all contribute to the amount and type of endothelial cell dysfunction present. A number of dynamic biophysical factors such as the type of flow in tumor and peritumoral vessel ${ }^{65}$ and perfusion pressure 66,67 in these vessels then determine the final amount of tumor-associated edema seen. At various stages of tumor growth, one mechanism may predominate and specific tumors may be associated with only one particular mechanism for edema formation. The effectiveness of any anti-edema therapy may be primarily determined by the ability of that therapy to modulate the underlying mechanisms of edema formation in that specific tumor. The development of new therapies to modulate human tumor-associated edema will have to be based on the elucidation of the exact mechanisms responsible for edema in the wide variety of clinical tumors seen.

\section{ACKNOWLEDGEMENTS}

The authors wish to acknowledge Mr. Eric Stroude for his technical expertise and Mrs. Jo-Ann Dunn for her secretarial assistance. This work was supported by the Upjohn Company, Revtech Research Lid. and the Brain Research Fund Foundation. Dr. Del Maestro is a recipient of an Ontario Ministry of Health Career Scientist Award and Drs. Megyesi and Farrell are supported by Medical Research Council of Canada Fellowships.

\section{REFERENCES}

1. Farrell CL, Stewart PA, Del Maestro RF. A new rat glioma model in rat: The $\mathrm{C} 6$ spheroid implantation technique, permeability and vascular characterization. J Neuro-Oncol 1987; 4: 403-415.

2. Megyesi JF, Del Maestro RF. Nuclear magnetic resonance in the investigation of cerebral tumors and cerebral edema: a clue to the cell alterations that may affect the distribution of water. Biochem Cell Biol 1988; 66: 1100-1109.

3. Barkowsky HM. Peritumoral edema. Prog Exp Tumor Res 1984; 27: 179-190.

4. Megyesi JF, Del Maestro RF. Nuclear magnetic resonance studies of human cerebral tumors. Can J Neurol Sci 1988; 15: 225. 
5. Kelly PJ, Duport-Daumas C, Kispert DB, et al. Imaging-based stereotaxic serial biopsies in untreated intracranial glial neoplasms. J Neurosurg 1987; 66: 865-874.

6. Folkman J. Angiogenesis. In: Jaffe EA, ed. Angiogenesis. The Hague: Martin Nijhoff $1984 ; 412-428$.

7. Hardman J. The angioarchitecture of the gliomata. Brain 1940; 63: 91-118.

8. Brem SS, Cotran RS, Folkman J. Angiogenesis in brain tumors: A quantitative histological study. Surg Forum 1974; 25 : 428-464

9. Stewart PA, Hayakawa K, Hayakawa E, et al. A quantitative study of blood brain barrier permeability ultrastructure in a new rat glioma model. Acta Neuropathol (Berl) 1985; 67: 96-102.

10. Coomber BD, Stewart PA, Hayakawa K, et al. Quantitative morphology of human glioblastoma multiforme microvessels: Structural basis of blood brain barrier defect. J Neuro-Oncol 1987; 5: 299-307.

11. Stewart PA, Magliocco M, Hayakawa $\mathrm{K}$, et al. A quantitative analysis of blood brain barrier ultrastructure in the aging human. Microvasc Res 1987; 33: 270-282.

12. Coomber BL, Stewart PA, Hayakawa EM, et al. A quantitative assessment of microvessel ultrastructure in C6 astrocytoma spheroids transplanted to brain and to Muscle. J Neuropathol Exp Neurol 1988; 47: 29-40.

13. Stewart PA, Hayakawa K, Farrell $\mathrm{CL}$, et al. Quantitative study of microvessel ultrastructure in human peritumoral brain tissue. J Neurosurg 1987; 67: 697-705.

14. Maiuri F, Gangem M, Cirillo S. Cerebral edema associated with meningiomas. Surg Neurol 1987; 27: 64-68.

15. Hamprecht B, Jaffe BM, Philpott GW. Prostaglandin production by neuroblastoma, glioma and fibroblast cell lines; stimulation by $\mathrm{N}^{6}, \mathrm{O}^{21}$-dibutyryl adenosine $3^{1}: 5$-cyclic monophosphate. FEBS Lett 1973; 36: 193-198.

16. Cooper C, Jones HG, Weller RO, et al. Production of prostaglandins and thromboxane by isolated cells from intracranial tumors. J Neurol Neurosurg Psychiatry 1984; 47: 579-584.

17. Ohnishi T, Shapiro WR. Vascular permeability factors produced by brain tumors: Possible role in peritumoral edema. Abstract J Neuro-Oncol 1987; 5: 179.

18. Bruce JW, Criscuolo GR, Merrill MJ, et al. Vascular permeability induced by a protein of malignant brain tumors: Inhibition by dexamethasone. J Neurosurg 1987; 67: 880-884.

19. Criscuolo GR, Merrill MJ, Oldfield EH. Further characterization of malignant glioma-derived vascular permeability factor. J Neurosurg 1988; 69: 254-262.

20. Chiu KM, Harris JE, Kroin JS, et al. The immunological response of Wistar rats to the intracranially implanted C6 glioma cell lines. J Neuro-Oncol 1983; 1: 365-372.

21. Palma L, Moschese V, Galli E, et al. Immunological studies in patients with central nervous system tumors. J Neuro-Oncol 1987; 5: 29-35.

22. Fontana A, Kristensen F, Dubs R, et al. Production of prostaglandin $\mathrm{E}$ and an interleukin-1-like factor by cultured astrocytes and $\mathrm{C} 6$ glioma cells. J Immunol 1982; 129: 2413-2419.

23. Lauro GM, Di Lorenzo N, Grossi $M$, et al. Prostaglandin $E_{2}$ as an immunomodulating factor released in vitro by human glioma cells. Acta Neuropathol 1986; 69: 278-282.

24. Fontana $A$, Hengartner $\mathrm{H}$, de Tribolet $\mathrm{N}$, et al. Glioblastoma cells release interleukin- 1 and factors inhibiting interleukin-2-mediated effects. J Immunol 1984; 132: 1837-1844.

25. Jacobs SK, Parham CW, Holcomb B, et al. Lymphokine activated killer (LAK) cell mediated killing of human glioma: Effect of pretreating glioma with various membrane modifying agents. J Neuro-Oncol 1987; 5: 5-10.

26. Barba D, Saris SC, Holder C, et al. Intratumoral LAK cell and interleukin-2 therapy of human gliomas. J Neurosurg 1989; 70: 175-182.

27. Saris SC, Patronas NJ, Rosenberg SA, et al. The effect of intravenous interleukin-2 on brain water content. J Neurosurg 1989; 71: 169-174.

28. Shinonaga $M$, Chang CC, Suzuki N, et al. Immunohistological evaluation of macrophage infiltrates in brain tumors. Correlation with peritumoral edema. J. Neurosurg. 1988; 68: 259-265.
29. Del Maestro RF. An approach to free radicals in medicine and biology. Acta Physiol Scand Suppl 1980; 492: 153-168.

30. Del Maestro RF. Free radical injury during inflammation. In Armstrong D, Sohal RS, Cutler RG, Slater TF, eds. Free Radicals in Molecular Biology, Aging and Disease. New York: Raven Press 1984: 87-101.

31. Werns SW, Lucchesi BR. Leukocytes, oxygen radicals and myocardial injury due to ischemia and reperfusion. Free Rad Biol Med 1987; 4 : 31-37.

32. Weiss SJ. Oxygen, ischemia and inflammation. Acta Physiol Scand Suppl 1986; 548: 9-37.

33. Svensjo E, Arfors KE, Arturson G, et al. The hamster cheek pouch preparation as a model for studies of macromolecular permeability of the microvasculature. Uppsala J Med Sci 1978; 83: 71-79.

34. Black KL, Hoff JT, McGillicuddy JE, et al. Increased leukotriene $\mathrm{C} 4$ and vasogenic edema surrounding brain tumors in humans. Ann Neurol 1986; 19: 592-595.

35. Moskowitz MA, Kiwak KJ, Hekimian K, et al. Synthesis of compounds with properties of leukotrienes C4 and D4 in gerbil brains after ischemia and reperfusion. Science $1984 ; 224$ : 886889.

36. Abdel-Halim MS, Sjoquist B, Anggard E. Inhibition of prostaglandin synthesis in rat brain. Acta Pharmacol Toxicol 1978; 43: 266-272.

37. Reichman HR, Farrell CL, Del Maestro RF. Effects of steroids and nonsteroidal anti-inflammatory agents on vascular permeability in a rat glioma model. J Neurosurg 1986; 65: 233-237.

38. Farrell CL, Megyesi JF, Del Maestro RF. The effect of ibuprofen on tumor growth in the C6 spheroid implantation glioma model. J Neurosurg 1988; 68: 925-930.

39. Del Maestro RF, Bjork J, Arfors KE. Increase in microvascular permeability induced by enzymatically generated free radicals. Part I. In vivo study. Microvas Res 1981; 22: 239-254.

40. Del Maestro RF, Bjork J, Arfors KE. Increase in microvascular permeability induced by enzymatically generated free radicals. Part II. Role of superoxide anion radicals, hydrogen peroxide and hydroxyl radical. Microvas Res 1981;22: 255-270.

41. Kontos HA. Oxygen radicals in cerebral vascular injury. Circ Res 1985; 57: 508-516.

42. Ley K, Arfors KE. Changes in macromolecular permeability by intravascular generation of oxygen derived free radicals. Microvas Res 1982; 24:25-33.

43. McCord JM. Oxygen derived free radicals in post-ischemic tissue injury. N Engl J Med 1985; 312: 159-163.

44. Halliwell B. Biochemical mechanisms accounting for the toxic action of oxygen on living organisms: The key role of superoxide dismutase. Cell Biol Int Rep 1978; 2: 113-128.

45. Braughler JM, Pregenzer JF, Chase RL, et al. Novel 21-amino steroids as potent inhibitors of iron dependent lipid peroxidation. J Biol Chem 1987; 262: 10438-10440.

46. Hall ED, Yonkers PA. Attenuation of post-ischemic cerebral hypoperfusion by the 21-aminosteroid U74006F. Stroke 1988; 19: 340-344.

47. Hall ED, Berry KP, Braughler JM. The 21 -aminosteroid lipid peroxidation inhibitor $\mathrm{U} 74006 \mathrm{~F}$ protects against cerebral ischemia in gerbils. Stroke 1988; 19: 997-1002.

48. Hall ED, Yonkers PA, McCall JM, et al. Effects of the 2l-aminosteroid $\mathrm{U} 740056 \mathrm{~F}$ on experimental head injury in mice. $\mathrm{J}$ Neurosurg 1988; 68: 456-461.

49. Zuccarello $M$, Anderson DK. Protective effect of a 21-aminosteroid on the blood-brain barrier following subarachnoid hemorrhage in rats. Stroke 1989; 20:367-371.

50. Megyesi JF, Farrell CL, Del Maestro RF. Investigation of an inhibitor of lipid peroxidation (U74006F) on tumor growth and protein extravasation spheroid implantation model. J NeuroOncol. In Press.

51. Nakagawa H, Groothius DR, Owens ES, et al. Dexamethasone effects on (125I) albumin distribution in experimental RG-2 gliomas and adjacent brain. J Cereb Blood Flow Metab 1987; 7: 687-701.

52. Selker RG. Corticosteroids: Their effects on primary and metastatic brain tumors. In: Walker MW, ed. Oncology of the Nervous System. The Hague: Martin Nijhoff 1983; 167-191. 
53. Saul TG, Ducker TB, Saleman M, et al. Steroids in severe head injury: A prospective randomized clinical trial. J Neurosurg 1981; 54: 596-600.

54. Norris JW. Steroid therapy in acute cerebral infarction. Arch Neurol 1976; 33: 69-71.

55. Poungvarin N, Bhoopat W, Viriyauejakul A, et al. Effects of dexamethasone in primary supratentorial intracerebral hemorrhage. N Engl J Med 1987; 316: 1229-1233.

56. Schroeder KA, McKeever PE, Schaberg DR, et al. Effect of dexamethasone on experimental brain abscess. J Neurosurg 1987; 66: 264-269.

57. Lebel MH, Freij BJ, Syrogiannopoulos GA, et al. Dexamethasone therapy for bacterial meningitis. Results of two double-blind, placebo controlled trials. N Engl J Med 1988; 319: 964-971.

58. Fishman RA. Brain edema. N Engl J Med 1975; 293: 706.

59. Weissman DE, Dufer D, Vogel V, et al. Corticosteroid toxicity in neuro-oncology patients. J Neuro-Oncol 1987; 5: 125-128.

60. Ackerman NB, Makohon S. The effects of steroidal and nonsteroidal anti-inflammatory agents on vascular permeability in intrahepatic tumors. Int J Microcirc Clin Exp 1982; 1: 253.
61. Siegal T, Siegal TZ, Shapira Y, et al. Indomethacin and dexamethasone treatment in experimental neoplastic spinal cord compression: Part 1. Effect on water content and specific gravity. Neurosurg 1988; 22: 328-334.

62. Siegal T, Shohami E, Shapira Y, et al. Indomethacin and dexamethasone treatment in experimental neoplastic spinal cord compression: Part 2. Effect on edema and prostaglandin synthesis. Neurosurg 1988: 22: 334-338.

63. Weismann DE, Stewart C. Experimental drug therapy of peritumoral brain edema. J Neuro-Oncol 1988; 339-342.

64. Del Maestro RF, Mattar AG. The influence of ibuprofen on patients with peritumoral edema. Can J Neurol Sci 1988; 15: 227.

65. Farrell CL. The microcirculation in a glioma model. Ph.D. Thesis. University of Western Ontario, 1988.

66. Durward Q, Del Maestro RF, Amacher Al, et al. The influence of systemic arterial pressure and intracranial pressure on the development of cerebral vasogenic edema. J Neurosurg 1983; 59: 803-809.

67. Vriesendorp FJ, Pasternak JF, Groothius DR. The effect of systemic arterial hypertension blood-to-tissue transplant in experimental gliomas. J Neuro-Oncol 1987; 5: 289-297. 